\title{
La repolitización de la sociedad como sentimentalización de la política. ¿Superación del privatismo civil?
}

\author{
Repoliticization of Civil Society as Sentimentalization \\ of Politics. Overcoming of Civil Privatism?
}

CÉSAR ORTEGA-ESQUEMBRE (Universitat de València) y MIGUEL ORTEGA (Universidad de Murcia)

Artículo recibido: 30 de marzo de 2019

Solicitud de revisión: 16 de octubre de 2019

Artículo aceptado: 28 de enero de 2020

Ortega-Esquembre, César y Ortega, Miguel (2021). La repolitización de la sociedad como sentimentalización de la política. ¿Superación del privatismo civil? Recerca. Revista de Pensament i Análisi, 26(2), 1-22. doi: http://dx.doi.org/10.6035/recerca.3823

Resumen

El presente artículo se propone analizar el par conceptual privatismo civil / politización de la sociedad. El objetivo es cuestionar si una de las formas concretas que adoptan hoy los procesos de repolitización de la sociedad civil, a saber, el llamado politainment y la sentimentalización del relato político, constituye o no una superación del privatismo civil. Para ello reconstruiremos primero la aparición del privatismo civil en el capitalismo tardío. En segundo lugar, analizaremos el surgimiento de esa conciencia ciudadana participativa que tiene su germen en los movimientos sociales de protesta posmaterialistas de finales de los sesenta. En tercer lugar, estudiaremos los procesos de sentimentalización y espectacularización del relato político. Sobre la base de este recorrido, en último lugar argumentaremos en contra de la tesis de una superación del privatismo civil.

Palabras clave: infotainment, politainment, privatismo, sociedad civil, politización.

\section{Abstract}

The aim of this paper is to analyse the relation between "civil privatism" and "politicization of society". We try to question whether or not one of the concrete current forms of repoliticization of civil society, namely the so-called "politainment", constitutes an overcoming of privatism. To achieve it, we first reconstruct the emergence of civil privatism in the late capitalism. We analyse second the rise of the processes for citizen participation 
in the framework of social protest movements in the late $1960 \mathrm{os}$. Third, we study current processes of sentimentalization and spectacularization of politics. On this basis, fourthly and lastly we argue against the thesis of an overcoming of civil privatism.

Key Words: infotainment, politainment, privatism, civil society, politicization.

\section{INTRODUCCIÓN}

Una de las consecuencias más interesantes de los procesos modernos de aceleración social es el rápido envejecimiento de las teorías y los diagnósticos de la época. Marcos conceptuales hasta hace poco explicativos resultan falseados y, a no ser que uno se atrinchere en la vieja postura de una teoría pura presuntamente ajena al mundo, el observador social no tiene más remedio que reconocer su inserción en un contexto sociohistórico que le obliga a transformar sus enunciados al mismo ritmo acelerado en que se transforma la sociedad (Rosa, 2005). La «contracción del presente», por utilizar la feliz expresión de Herman Lübbe (Lübbe, 1998), desmiente cada vez más rápidamente la validez de teorías sociales que trataron de apresar conceptualmente dicho presente.

Aunque semejante desmentido afecta a multitud de tesis provenientes de la filosofía política y las ciencias sociales, los diagnósticos sobre la relación entre sociedad civil y vida política constituyen un caso particularmente interesante. Desde las comprensiones altamente idealizantes de la ciudadanía política desarrolladas por el pensamiento republicano que va de Rousseau a Philip Pettit (Rousseau, 1988; Pettit, 1999), hasta las reivindicaciones actuales de una «epistocracia» contraria al sufragio universal (Brennan, 2016), pasando por la teoría elitista de la democracia de Joseph Schumpeter (Schumpeter, 1988), donde al ciudadano le queda reservada la tarea de elegir entre diferentes «mercaderías políticas», o por las revitalizaciones de la sociedad civil emprendidas por los teóricos de la democracia deliberativa (Habermas, 2010b; Bohman y Rehg, 1997; García-Marzá, 2016; Cortina, 1993), a lo largo de la historia del moderno pensamiento político ha existido un vaivén de diagnósticos descriptivos y normativos sobre la función política de la sociedad civil.

El presente artículo se propone estudiar, desde un punto de vista teórico, el par conceptual privatismo civil / politización de la sociedad en el contexto de los Estados sociales y democráticos de derecho occidentales. Dentro de este marco, se pretende cuestionar si una de las formas concretas que adoptan hoy los procesos de repolitización de la sociedad civil, a saber, la espectacularización 
mediática de la política, constituye o no una superación del privatismo civil. Para ello reconstruiremos en primer lugar la aparición del privatismo civil en el periodo histórico llamado capitalismo tardío democrático, es decir, el periodo de instauración y consolidación del Estado del bienestar que va desde 1945 hasta finales de los años setenta. Tras exponer, recurriendo a la literatura especializada, el surgimiento de esa conciencia ciudadana participativa que tiene su germen en los movimientos sociales de protesta de finales de los años sesenta, estudiaremos en tercer lugar los procesos de sentimentalización y espectacularización del relato político. Este tercer punto será emprendido a modo de una revisión exhaustiva de la bibliografía especializada. Sobre la base de este recorrido, en cuarto y último lugar interpretaremos, en términos filosóficopolíticos, el significado social de esta espectacularización mediática de la política, indagando si semejante fenómeno corrobora o no la tesis de una superación del privatismo civil.

\section{EL PRIVATISMO CIVIL EN EL CAPITALISMO TARDÍO}

En su repaso histórico por las formas de distribución de la riqueza desde el siglo XVIII hasta la actualidad, Thomas Piketty ha documentado una espectacular caída de los índices de desigualdad económica en las sociedades occidentales a partir de 1945. Este fenómeno se explica observando la disminución del peso de los ingresos por capital en relación con los ingresos por trabajo, fenómeno cuya causa, a su vez, Piketty sugiere buscar en la destrucción masiva de patrimonios privados durante las dos guerras mundiales y en las posteriores políticas keynesianas de estimulación de la demanda, tributación y control público del capital (Piketty, 2014: 56). Semejante dispersión de la riqueza, junto con la consolidación del Estado del bienestar y el surgimiento del sistema de partidos políticos de masas (Offe, 1988), tuvo como consecuencia una suerte de «domesticación democrática» (Habermas, 2010b) del antiguo capitalismo liberal. El modelo jurídico ligado al Estado social surgió por lo demás a modo de una crítica reformista al paradigma del derecho formal burgués anterior, tan pronto como se hizo evidente que la protección de los derechos civiles, es decir, el estatus negativo de los sujetos jurídicos, no garantizaba por sí misma la justicia social (Habermas, 2010b: 482).

Esta domesticación democrática de la economía, a veces denominada con-

senso keynesiano, hizo evidente que la superación de las contradicciones sociales no requería esa revolución del modo burgués de producción que Marx, y aún 
los marxistas de los años treinta, había creído inevitable (Marx, 1970: Prefacio), sino tan solo el aseguramiento de una demanda de productos tal que su producción exigiera el mantenimiento del pleno empleo (Keynes, 1986). Ahora bien, semejante intervencionismo estatal, que en el capitalismo tardío toma la forma de políticas sociales y una política económica de estimulación de la demanda, hace que el Estado vuelva a requerir, como ocurriera en las sociedades preburguesas, una fuente de legitimación allende las lógicas del mercado. Puesto que en la modernidad esta legitimación no puede ya provenir de fuentes tradicionales como las cosmovisiones religioso-metafísicas, el sistema político tiene que recurrir a un lugar nuevo. Este lugar es la democracia formal y el privatismo civil: el sistema administrativo, autonomizándose de una genuina formación participativa de la voluntad política y garantizando dignas condiciones materiales de vida para las clases trabajadoras, consigue mantener en estado de latencia la contradicción existente entre «una producción administrativamente socializada y un modo de apropiación de la plusvalía que sigue siendo privado» (Habermas, 1973: 53). Algunos teóricos sociales como Jürgen Habermas o Claus Offe se han referido a este fenómeno con el nombre de «paralización de la lucha de clases». ${ }^{1}$

En el contexto de lo público despolitizado, la legitimación del sistema solo exigía ofrecer al ciudadano ciertas recompensas de bienestar y participación mínima que, como había visto Herbert Marcuse a mediados de los años sesenta, no solo no ponían en riesgo la estabilidad del sistema, sino que contribuían a una permanente reproducción de lo existente (Marcuse, 1985: 80 y ss.). Según esta lectura, que opera obviamente en clave crítico-ideológica, estas recompensas dosificadas tienen el objetivo de satisfacer necesidades privatizadas, que terminan por disolver la identidad de clase y evitan el estallido de aquellas crisis sistémicas a que se veían abocadas las sociedades del capitalismo liberal.

Ahora bien, esta inmunización contra las crisis sistémicas, así como los evidentes logros normativos derivados de la compatibilización entre capitalismo y democracia, no evitan que las sociedades tardocapitalistas enfrenten una serie de tendencias a la crisis de tipo diferente. No solo los peligros del privatismo civil y la fragmentación de los potenciales de resistencia colectiva

\footnotetext{
Axel Honneth ha denunciado una «despedida inflacionaria del proletariado» en la tesis de la paralización de la lucha de clases. A su juicio, esta tesis no interpreta correctamente la estructura de clases del capitalismo tardío. Reduciendo la noción de oportunidades de vida a la dimensión de bienes materiales, la explicación no advierte que la teoría de clases aplicada al capitalismo tardío «tiene que ser ampliada a la distribución asimétrica de oportunidades de vida culturales y psíquicas». Honneth se refiere, por supuesto, a las oportunidades de reconocimiento social que garantizan la identidad. Véase Honneth, 2011; Giddens, 1979.
} 
asociados a la nueva cultura del capitalismo tardío (Taylor, 1994: 136 y ss.), sino también la estandarización de formas de vida (Marcuse, 1985; Adorno, 1953), los procesos de burocratización de relaciones sociales derivados del intervencionismo estatal (Habermas, 2010a), los límites inmanentes al aumento del gasto público (Offe, 1990), el amalgamiento de necesidades y deseos (Bell, 1977), las crisis ecológicas derivadas del crecimiento del sistema productivo y las crisis de motivación (Habermas, 1973), hicieron que durante los años setenta y ochenta surgiera un nutrido número de críticas al Estado del bienestar. En nuestro contexto, no obstante, resultan especialmente relevantes los enfoques centrados en las llamadas crisis políticas de legitimación (Habermas, 1973), que pueden obedecer, si lo entendemos correctamente, a dos lógicas diferentes.

En primer lugar, las crisis de legitimación afloran tan pronto como la estructura de clases mantenida en estado de latencia reaparece en la conciencia ciudadana, es decir, cuando surgen «expectativas que no pueden satisfacerse con recompensas conformes al sistema» (Habermas, 1973: 94). Tal cosa ocurre de manera paradigmática una vez que, con el progresivo agotamiento de los amortiguadores del Estado del bienestar y el incremento de las desigualdades económicas, reaparecen grandes masas de población que vuelven a tener razones para protestar contra una distribución del producto social renovadamente injusta. Estos movimientos de protesta se intensificaron, naturalmente, conforme el antiguo capitalismo domesticado fue dando paso, con el triunfo del ideario neoconservador y la política económica neoliberal, a una nueva fase de desregulación económica. En segundo lugar, las crisis de legitimación surgen cuando las expectativas de los ciudadanos no solo no pueden ser satisfechas de acuerdo con la actual forma de organización del modo productivo, sino que más bien no tienen nada que ver con el modo productivo. Esto explica que los movimientos sociales de finales de los años sesenta y los años setenta adoptaran orientaciones de valor que hoy llamamos posmaterialistas.

\section{REPOLITIZACIÓN Y NUEVOS MOVIMIENTOS SOCIALES}

Las dos lógicas anteriores hacen referencia a los dos tipos de sistemas de valores tipificados por Ronald Inglehart bajo los epígrafes materialistas y posmaterialistas (Inglehart, 1971). Según la conocida tesis de Inglehart, a finales de los años sesenta pudo observarse, por vez primera en la historia de Occidente, una significativa diferencia entre las prioridades valorativas de las generaciones jóvenes y las generaciones ancianas. Mientras que entre los estratos pobla- 
cionales de mayor edad primaban valores materialistas, que enfatizaban sobre todo la seguridad económica y física, entre los sectores jóvenes - los que habían nacido después de 1945 , que por entonces tenían menos de 25 añosprimaban valores posmaterialistas, que enfatizaban aspectos como la autonomía, la autoexpresión, la participación política o la libertad de expresión. La hipótesis avanzada por Inglehart a comienzos de los años setenta era que semejante cambio axiológico intergeneracional no se explicaba por la variable del ciclo vital, sino más bien de acuerdo a factores vinculados con la variación de las condiciones de existencia, que después de 1945 mejoraron como nunca antes en la historia de Occidente. Las personas socializadas en condiciones de existencia prósperas - tal era la tesis - tendían a desarrollar sistemas axiológicos desvinculados de las antiguas exigencias materialistas. En trabajos más recientes, Inglehart ha logrado validar esta hipótesis estudiando las preferencias valorativas de aquellas generaciones jóvenes que iniciaron el primer cambio y que hoy, tras haberse convertido a su vez en generaciones ancianas, mantienen una tendencia posmaterialista (Inglehart, 2008).

Apoyados en este marco teórico, es fácil observar en qué sentido el par conceptual privatismo civil / politización de la sociedad experimentó un nuevo y fundamental cambio tan pronto como la realidad social desmintió, una vez más, el marco explicativo establecido. Es decir, tan pronto como, con la irrupción de movimientos sociales de tipo posmaterialista, primero, y con la crisis del Estado del bienestar y la removilización de protestas materialistas, después, se resquebrajaron los cimientos que aseguraban el privatismo civil.

Con respecto al segundo elemento, si la relación existente entre capital privado y capital público había manifestado una tendencia claramente descendente desde 1914, a partir de la década de 1960 se inició una tendencia inversa, que dura hasta nuestros días, y que ha conseguido alcanzar niveles de patrimonio privado y desigualdad no vistos desde la Belle Époque (Piketty, 2014). Las políticas de privatización, reducción de la presión fiscal y desregulación de los mercados financieros, que pudieron surgir solo en el contexto de una economía mundializada y una progresiva disminución de la capacidad de acción del Estado-nación (Beck, 1998; Hobsbawm, 2011: 284), favorecieron naturalmente este proceso. Una de las consecuencias más importantes de esta mundialización de la economía ha sido el descenso de los salarios de los trabajadores no cualificados del primer mundo, de acuerdo con el llamado «factor de la equiparación de precios» (Thurow, 1996: 169). Con el advenimiento de lo que algunos autores llaman «capitalismo cognitivo» (Moulier Boutang, 2004), la dicotomización del sistema ocupacional amenaza con volverse crónica 
(Honneth, 1994: 132; Pereira, 2007), de suerte que no resulta exagerado hablar de una auténtica «secesión de los ricos» (Romero y Ariño, 2016).

Aunque, por supuesto, la política económica y la globalización no son las únicas causas de la quiebra del Estado social, sino que es preciso recurrir a otros fenómenos como el progresivo envejecimiento de la población occidental -y el consecuente peligro de colapso del sistema de jubilaciones- o el aumento estructural del desempleo - consecuencia, entre otras cosas, de una automatización de la fuerza de trabajo que busca reducir los altos costes derivados de los derechos de los trabajadores-, lo cierto es que, con la tendencia neoliberal de la política económica, el logro de un capitalismo domesticado por el Estado social amenaza con disolverse. Y con él también las bases que garantizaron el privatismo civil en el periodo de posguerra. Los actuales movimientos de protesta antiausteridad, entre los que ocupan un lugar destacado las plataformas destinadas a combatir los desahucios (Ordóñez, Feenstra y Tormey, 2015); unos movimientos que, obviamente, operan bajo orientaciones de valor materialista, suponen el ejemplo más sintomático de esta segunda forma de resquebrajamiento del privatismo civil.

Ahora bien, lo más interesante de la nueva situación no es tanto la revitalización de movimientos de protesta materialistamente orientados, cuanto el surgimiento de nuevos frentes de resistencia totalmente incomprensibles desde las viejas categorías empleadas por liberales y marxistas. Hacia finales de los años sesenta, y sobre todo durante los años setenta, aconteció una repolitización de la sociedad civil bajo la forma de movimientos sociales apoyados en preferencias valorativas posmaterialistas: el movimiento estudiantil, los grupos pacifistas y ecologistas, el movimiento feminista, los movimientos por los derechos civiles de las minorías étnicas, la contracultura o las reivindicaciones de la democracia radical, entre otros, no pretendían poner en consonancia los imperativos funcionales de los subsistemas económico y político con sus propias necesidades de seguridad física, sino cuestionar directamente la legitimidad de tales imperativos funcionales.

A pesar de las fluctuaciones en esta tendencia posmaterialista, es decir, de aquella reaparición de reivindicaciones de tipo materialista que puede comprenderse, siguiendo la tesis de Inglehart, como la consecuencia de crisis económicas transitorias, la tendencia iniciada a finales de los años sesenta ha supuesto un creciente énfasis en valores y movimientos sociales vinculados con los derechos civiles, el medio ambiente o la participación en la toma de decisiones económicas y políticas. Para los intereses de nuestra argumentación, las reivindicaciones de la llamada democracia radical, que hoy adquiere nuevos 
impulsos de las posibilidades ofrecidas por las nuevas tecnologías, revisten obviamente un interés especial. Al margen de la exactitud de la tesis de Inglehart, que de ser exacta hoy habría de alumbrar un crecimiento significativo de aquellos jóvenes materialistas cuya socialización temprana ocurrió en la fase de inseguridad económica de la gran recesión, lo cierto es que las jóvenes generaciones tienden a participar en formas de acción política no institucionalizada o extraparlamentaria, lo cual parece ser un rasgo típico de las orientaciones de valor posmaterialista (Henn, Oldfield y Hart, 2018). Esta tendencia tal vez pudiera reflejar el generalizado rechazo a las políticas de austeridad y sus efectos manifiestamente negativos para las generaciones más jóvenes.

Tal y como ha visto Helmut Dubiel, en el transcurso de los años setenta la antigua oposición democracia liberal / totalitarismo, que se había hecho valer todavía en las primeras décadas de posguerra a contraluz de regímenes como los de Portugal, España o la Unión Soviética, quedó disuelta en favor de la oposición democracia elitista/democracia participativa (Dubiel, 1993: 46; Macpherson, 2003). Esta oposición queda ejemplificada en el debate intelectual, desarrollado en las décadas de los setenta y ochenta tanto en Estados Unidos como en Europa, entre la teoría crítica del capitalismo tardío (Habermas, 1973; 2010a) y los representantes del neoconservadurismo (Bell, 1977). La «radicalización intensiva y extensiva del principio democrático» (Dubiel, 1993: 48), que los representantes de la teoría crítica interpretaron como un saludable aumento de exigencias de legitimación democrática que podía poner en riesgo la estabilidad de un sistema habituado al privatismo, era interpretada por el pensamiento neoconservador mediante esa tesis de la ingobernabilidad, según la cual «un exceso de democracia hace peligrar la existencia de las sociedades liberales» (Dubiel, 1993: 47).

Pese a esta conocida consiga, que, junto con el monetarismo en el ámbito económico, el tradicionalismo en el ámbito cultural y el belicismo en el terreno de la política exterior, define el núcleo del pensamiento neoconservador (Habermas, 1997: 36), lo cierto es que la precarización de grandes masas de población, que un Estado social en descomposición apenas puede ya compensar, y el surgimiento de nuevos conflictos sencillamente inasumibles desde un paradigma productivista, viene fomentando desde los años setenta una evidente y duradera repolitización de la sociedad civil, que en la era de las nuevas tecnologías de la información y la comunicación adopta unos rasgos totalmente imprevisibles para la teoría social anterior. 


\section{LA REPOLITIZACIÓN DE LA SOCIEDAD CIVIL COMO ESPECTACULARIZACIÓN DE LA POLÍTICA}

En un contexto social caracterizado por la creciente desafección hacia la clase política y por unas «políticas del malestar» (Pardo, 2018) que, instaladas en la retórica del conflicto y el oportunismo (Jacobs y Shaprio, 200o), tienden a dividir a la sociedad en distinciones binarias reduccionistas como «héroes y villanos», «triunfos y desastres» o «inocentes y culpables» (Innerarity, 2015: 168), los votantes parecen abandonar progresivamente su antigua condición de meros espectadores de la actividad política institucionalizada (Mancini y Swanson, 1996: 16-17) para empoderarse en una serie de formas de participación política desafiantes para la élite (Inglehart, 1999). Este progresivo empoderamiento de la ciudadanía conduce hoy a una sentimentalización de la conversación pública que se desarrolla en paralelo a la crisis de la comunicación política tradicional. Semejante giro afectivo de la política provoca, entre otros fenómenos, una batalla por la captación de las emociones de los votantes, de suerte que no son pocos los autores que, entroncando con la teoría de la inteligencia afectiva y con los estudios de la neuropolítica, tienden a hablar del «cerebro político» como «cerebro emocional» (Westen, 2008).

Una de las principales causas de la mencionada polarización ideológica y del deterioro de la calidad de la conversación pública se encuentra en el desarrollo imparable de las tecnologías de la información, que propician fenómenos como las fake news o la mediocracia. Esta última, entendida como la capacidad de los medios de comunicación para penetrar en la conciencia pública y orientar las posiciones ideológicas de los ciudadanos (Conill y Gozálvez, 2004), provoca que el orden social y político devenga, de forma creciente, en un orden mediático. Debido a este fenómeno, el periodismo se sitúa en un lugar central en el entramado social (Casero-Ripollés, 2012). En el contexto de una indignación impermeable en ocasiones al señalamiento de las causas o la discusión de las soluciones; en el contexto de una negatividad que, por cierto, algunos autores saludan como una nueva fuerza creativa destacada por su capacidad para la disrupción del orden vigente (Arias Maldonado, 2016: 22), cobra especial relevancia el surgimiento del llamado Wutbürger, un vocablo de origen alemán traducido literalmente como 'ciudadano rabioso'. ${ }^{2}$ La ciudadanía, cada vez más, abandona las lógicas de las organizaciones tradicionales y responde ante la política con una visión desencantada y cínica. La negatividad

\footnotetext{
2 En el 2010, Wutbürger fue denominada la palabra del año por la Gesellschaft für deutsche Sprache.
} 
se ubica, en este contexto, en el centro de un discurso político focalizado en la crítica del adversario, la búsqueda de la movilización de los adeptos y la desmovilización de los rivales (Sampedro y Seoane, 2008).

Ahora bien, y esto es lo importante para nosotros, el descrédito hacia las líneas oficiales del pensamiento político, que moviliza sin duda a los ciudadanos en direcciones diferentes a las hasta ahora conocidas, es aprovechado por las empresas mediáticas para atraer consumidores (Bernhardt, Krasa y Polborn, 2006). La repolitización del espacio público, como veremos más adelante, toma así la forma de una espectacularización de la política. En este contexto adquiere todo su sentido el mencionado auge de la lucha por la captación de las emociones de los votantes. Arias Maldonado menciona el ascenso del hombre emocional en la cultura pop, mientras que José Andrés Fernández alerta sobre el exceso de romanticismo inherente al giro afectivo de la política. Este fenómeno es calificado por Drew Western como sentimentalismo tóxico, ya que en la lógica en la que prevalece el imperio de los sentimientos el votante racional queda reducido a la categoría de mito, puesto que el afecto sesga irremediablemente el procesamiento de la información (Arias Maldonado, 2016). En el contexto de lo que Mazzoleni y Sfardini han denominado política pop, el espectáculo ha invadido un territorio reservado durante décadas al ámbito puramente informativo. La apuesta por nuevas narrativas y estéticas basadas en el protagonismo de las emociones (Uribe y Gunter, 2007) genera asimismo una personalización en la transmisión de la política.

Siguiendo esta antropología pesimista, Arias Maldonado profundiza con su estudio sobre las patologías de la racionalidad en la idea de las distorsiones decisorias que afectan a la toma de decisiones colectivas, y entre las cuales destacan los «efectos de cascada, enmarcamiento de los hechos, diferente visibilidad de un tipo u otro de información, aversión a la pérdida, procrastinación», etc. En la línea de pensamiento del filósofo Richard Potkin, este marco interpretativo sostiene que el votante es un avaro cognitivo, puesto que suele tener unas creencias prefijadas que trata de apuntalar con el mínimo de información posible (Arias Maldonado, 2016: 75). De lo apuntado anteriormente podemos concluir que los mensajes que apelan a la emoción, además de ser más y mejor recordados, generan un contagio emocional y se difunden con más rapidez que los contenidos donde se privilegia el razonamiento y la cognición (Hatfield, Cacioppo y Rapson, 1994).

Dentro de este marco teórico caracterizado por el malestar y la apelación continua a la emoción, la comunicación política, entendida como ciencia que se encarga de la diseminación de la producción informativa, se encamina en 
las últimas décadas hacia una progresiva espectacularización en sus contenidos y lenguajes. La repolitización de la sociedad civil se desarrolla dentro de unas lógicas comerciales en las que la mercantilización de la información cobra protagonismo y las noticias pasan a ser concebidas como productos (Mosco, 2009). Blumer y Gurevitch (1995) ya advirtieron del peligro de la trivialización de la información política y la creciente profesionalización de su gestión desde el poder, en lo que se ha llamado «la crisis de la comunicación pública» (Rodríguez-Polo y Martín-Algarra, 2012: 77-90).

En la actualidad, la televisión, pese al surgimiento y consolidación de la comunicación a través de las redes en línea, mantiene su predominio como el canal más eficaz para la rápida penetración en las audiencias. El incremento progresivo de la competitividad en el mercado televisivo, exacerbado por la incorporación diaria de nuevos competidores, induce a las televisiones generalistas a practicar políticas editoriales masivas y poco originales. La diversidad genérica es un lujo que apenas encuentra ya acomodo en las parrillas públicas (Contreras y Palacio, 2001).

El llamado infoentretenimiento, conocido también como politainment, alude a la tendencia de los medios de comunicación a presentar la información en clave espectacular, especialmente a través de la televisión, con el fin último de popularizar la información política. La profesora Salomé Berrocal señala que la devaluación en la presencia de noticias de análisis o de desarrollo (hard news) conduce a la incorporación de noticias ligeras (soft news) destinadas prioritariamente a la distracción del espectador (Berrocal, 2017). Existe un consenso académico en que el nacimiento mundial del fenómeno del infoentrenimiento data de 1992, cuando el expresidente norteamericano Bill Clinton tocó el saxofón en directo en el magazine The Arsenio Hall Show. En España, el programa televisivo Las noticias del guiñol, emitido por Canal +, se convirtió en el primer espacio que recogía los estilemas propios de esta progresiva espectacularización. En el politainment, el periodista se convierte en coprotagonista de la información (Ortells-Bádenes, 2011), haciendo uso de un estilo narrativo en el que prima la descontextualización, la personalización, el dramatismo y el humor (Berrocal, 2017). En cuanto a las particularidades técnicas del fenómeno, Lozano apunta a una serie de rasgos definitorios como son el plano subjetivo, la música dramática, la ralentización de las imágenes y los efectos de posproducción (Lozano, 2004). Las razones del éxito radican principalmente en la rentabilidad económica, puesto que para los programadores resulta más barato producir este tipo de contenidos orientados primordial- 
mente a un nuevo público que no consume informativos (Kovach y Rosentiel, 2012). Según Lozano, estas son las características propias del politainment:

1. Dramatización. Énfasis en el conflicto. Alarmismo.

2. Fragmentación. Representación de los hechos de manera aislada sin alusiones al proceso previo.

3. Normalización. Simplismo en la propuesta de solución a los problemas.

4. Personalización. Reducción de la información a casos particulares.

5. Narración hiperbólica. Acento en la emotividad y sentimientos.

Con la neotelevisión, los conceptos fundacionales consistentes en formar, informar y entretener han sido ampliamente superados. El infoentretenimiento supone una hibridación (Salgado Losada, 2010) que reúne en un mismo espacio televisivo los rasgos propios de la información más tradicional con aquellos que caracterizan a los programas de entretenimiento, incorporando, además, sentimientos íntimos, tintes dramáticos o ingredientes cómicos (Berrocal, Campos-Domínguez y Redondo, 2012: 13-34), y buscando atraer al televidente a través de la hipérbole en la configuración de los contenidos. Debido a que las propuestas audiovisuales alcanzan a audiencias más heterogéneas y favorecen el entendimiento de los mensajes simples (Chaiken y Eagly, 1976), los programadores apuestan por una mezcla de géneros que desdibuja las fronteras entre el periodismo y el sensacionalismo.

La política como fenómeno espectacular, tal y como afirma Schwartzenber (1977), vive y sienta sus bases en la personalización del poder y la teatralización de la vida pública, lo que la convierte en política postiza. Debido a que la acción de gobierno se ha transformado en una actividad eminentemente pública y visible, surge un tipo de político caracterizado por su capacidad de seducción (Muñoz-Alonso y Rospir, 1995). En la comunicación política se potencian, de este modo, aquellos formatos en los que los candidatos puedan hacer de la política un show permanente. En este sentido, Gans incorpora el concepto de people stories, en el que se presentan historias de ciudadanos anónimos en situaciones extraordinarias o relatos conformados por detalles sobre la vida privada de los poderosos o celebridades públicas. Los relatos personales o storytelling apuestan por la humanización de los políticos, una herramienta que les permite establecer vínculos de proximidad con la ciudadanía que pueden derivar en la creación de lazos afectivos (Casero-Ripollés, Ortells-Bádenes y Rosique Cedillo, 2014: 45-54). Cuando apelamos al relato, apuntamos a la idea de transmitir valores y objetivos y a construir una cierta identidad alrededor de la coincidencia que se genera entre audiencia y orador (D'Adamo y García Beaudoux, 2016). La personalización se ha convertido en una fórmula 
exitosa. La utilización de un tipo de mensaje eminentemente persuasivo, que proyecta en los atributos personales del político su mensaje electoral, además de reforzar las nociones de poder incide directamente en conceptos como la autoridad o el liderazgo (Orejuela, 2009: 60-83). Por lo tanto, la imagen percibida por el votante es «una construcción mental subjetiva» (Nimmo y Savage, 1976) que representa al líder político. Esta imagen está condicionada por los estímulos sensoriales suscitados en la transmisión de la imagen y filtrada asimismo por el esquema mental, el nivel de conocimiento y de información del individuo (Mazzoleni, 2004). El objetivo del relato es la apelación a las emociones del receptor, siguiendo la estela de la llamada neuropolítica (GarcíaMarzá, 2013; Cortina, 2011; Pérez-Zafrilla, 2018), que busca rentabilizar el saber sobre los mecanismos neuronales subyacentes a la toma de decisiones de los votantes.

La vida privada de los políticos funciona como una distracción en unas sociedades cuyos niveles de politización efectiva no están ya tan claros como lo estuvieron durante los años setenta (Innenarity, 2015). Pese a todo, es preciso ser prudentes en lo que respecta a la influencia que esta presentación mediática de la vida privada de los políticos tiene en el electorado, pues, como vieron Margolis y Mauser ya en 1992, «en general, la influencia de los medios está limitada por normas y tradiciones de la sociedad. Tanto la familia como la escuela son condicionantes de la agenda individual y reordenan las prioridades de la existencia» (Margolis y Mauser, 1992). La estrategia de presentación de valores de los políticos aspira a que sea el destinatario quien, de un modo o bien autónomo o bien subsconsciente, extrapole esos rasgos de la vida privada del candidato a la esfera público-política (Vázquez Sande, 2017: 275-291).

En cualquier caso, es claro que en la comunicación política contemporánea los aspirantes se han convertido en los grandes expositores de la política de los partidos a los que representan. La importancia del fenómeno de la mediocracia se traduce en la participación de los políticos en espacios de entretenimiento, especialmente en infoshows. En estos escenarios, la cobertura política sufre una simplificación en la que se ofrecen elementos cínicos y negativos, enfoques personalistas, informaciones parciales y narraciones teatralizadas de la vida política (Berrocal, 2003). Que semejante espectacularización de la política sea una superación efectiva de las antiguas lógicas privatistas es algo que, sin embargo, no puede darse por supuesto sin más. 


\section{4. ¿SUPERACIÓN DEL PRIVATISMO CIVIL?}

Una vez presentado el fenómeno de la sentimentalización y espectacularización mediática de la política, así como su significado en el contexto de una sociedad civil cuya participación en la vida política ha resultado históricamente ambivalente, estamos en condiciones de avanzar una posible respuesta a la pregunta planteada en la introducción: ¿constituye este fenómeno una genuina superación del privatismo civil o no es más que una forma de protesta paradójicamente beneficiosa para los imperativos privatistas que supuestamente pretende quebrar?

Una respuesta categórica a esta pregunta resultaría probablemente demasiado simplista. Por una parte, el descentramiento del periodismo tradicional como discurso privilegiado para comunicar lo político, y su consecuente desplazamiento a espacios y lugares informales (Echeverría, 2017), provoca la desacralización de lo político y su popularización entre audiencias no educadas o tradicionalmente poco interesadas en la política. Cualquier observador, al margen de sus conocimientos sobre ciencias sociales, puede constatar este fenómeno con la mayor facilidad. La sentimentalización del relato político puede actuar en este sentido como un resorte capaz de hacer surgir en el ciudadano un interés hasta entonces inexistente en la cosa pública, lo cual, naturalmente, constituye el primer paso para quebrar el privatismo civil. Ahora bien, semejante movilización emocional del público solo puede resultar beneficiosa si se aplican los correctivos racionales necesarios, y es aquí donde los defensores de la espectacularización y sentimentalización de la política se ven confrontados con la carga de la prueba.

En primer lugar, aunque la promoción de planteamientos emocionales en la información política consigue mayores cuotas de público interesado, lo cierto es que no está nada claro que semejante aumento, obtenido como hemos visto mediante la banalización de las noticias, la reducción de la información a casos particulares, la creación de una agenda pública depauperada y la supresión del rigor conceptual del propio discurso político (Baumgartner y Morris, 2006), pueda ser comprendido sin más como una emancipadora politización de la sociedad civil. Una sociedad civil acostumbrada al eslogan político de corte emocional, a las visiones maniqueas y a la cultura del disenso no es desde luego el agente de ese «uso público de la razón» reivindicado por la filosofía política ilustrada que va de Kant a John Rawls. Por mucho que la defensa de esta comprensión racionalista y deliberativa de lo político sea profundamente antipática al aire de los tiempos. 
Además de ello, y en segundo lugar, la espectacularización de la política corre el riesgo de convertir a la sociedad civil, presunto agente de la transformación social, en cliente del mercado mediático. En el marco de lo que Habermas ha llamado democracia de doble vía, a la sociedad civil le corresponde la fundamental tarea de detectar nuevas fuentes de conflicto que preocupan a la ciudadanía y conformar informalmente una opinión política que, a modo de exigencias normativas, ha de trasladar a los espacios formales de decisión política (Parlamento). Cuando la acción de esta sociedad civil, que puede poner en duda la legitimidad del mercado mediático y contribuir indirectamente a su modificación -mediante exigencias normativas que solo en un segundo paso, tras su traducción al lenguaje del derecho, adquieren un carácter vinculante-, es usurpada por el propio mercado mediático $-\mathrm{y}$ tal cosa ocurre de manera paradigmática con la espectacularización mediática del discurso político-, entonces la diferenciación funcional entre la esfera de la sociedad civil y la esfera del mercado amenaza con quedar disuelta en favor de la segunda, y la politización ciudadana, lejos de contribuir a superar las lógicas privatistas, se convierte en una estilizada forma de mantener en estado de latencia, una vez más, los potenciales de protesta.

\section{CONCLUSIONES}

Un recorrido general por la dialéctica entre privatismo civil y politización en las recientes sociedades occidentales ha sacado a la luz una conclusión muy general: si durante el periodo de posguerra pudo consolidarse ampliamente en Europa una conciencia privatista, consecuencia por lo demás de un aumento realmente inédito del nivel de vida de las clases trabajadoras, a partir de los últimos años sesenta se inició un proceso de ininterrumpida politización de la sociedad civil. Semejante proceso arrancó sobre la base de una crisis de legitimación del capitalismo tardío que, si lo entendemos correctamente, obedecía a dos lógicas diferentes. En primer lugar, al surgimiento de movimientos sociales estructurados conforme a orientaciones de valor posmaterialistas, que incidían de forma especial en la profundización democrática de la sociedad. En segundo lugar, a la aparición de movimientos sociales que volvían a reivindicar aquellas exigencias materialistas mantenidas en estado de latencia por un Estado del bienestar entretanto desvigorizado.

En este contexto general, y sobre la base de una creciente desafección hacia la clase política y de una progresiva dicotomización de la sociedad, las úl- 
timas décadas han visto crecer una forma peculiar de politización ciudadana, cuyo rasgo más notable es sin duda la sentimentalización de los relatos. El escenario derivado de este giro afectivo de la política ha creado un suculento nicho de mercado para unas empresas mediáticas que luchan por la captación de consumidores de entretenimiento político. Aunque resulta difícil negar que esta espectacularización mediática de la política ha logrado aumentar el número de ciudadanos interesados en los asuntos públicos, hemos defendido que semejante incremento no puede comprenderse como una superación del privatismo civil más que al precio de traicionar el verdadero sentido de esta idea. Cuando los miembros de una sociedad civil devienen clientes del mercado mediático, los procesos de politización, que adoptan la forma de una espectacularización de los acontecimientos políticos, no constituyen -o al menos no de forma inmediata - una superación del privatismo. Antes bien, tales procesos se parecen mucho más a esas estrategias de usurpación de los espacios de formación autónoma de la opinión pública que algunos teóricos sociales de posguerra habían estudiado, en el clima del privatismo civil, bajo la paradójica fórmula de una teoría de la industria cultural. Que esta teoría pueda ser otra vez útil para nosotros acaso signifique que el desmentido de los diagnósticos de la época al que hacíamos referencia al comienzo de este trabajo no siempre resulta definitivo.

\section{BIBLIOGRAFÍA}

Adorno, Theodor W. (1953). Fernsehen als Ideologie. Rundfunk und Fernsehen, 4.

Arias Maldonado, Manuel (2016). La democracia sentimental. Política y emociones en el siglo XXI. Barcelona: Página Indómita.

Baumgartner, Jody C. y Morris, Jonathan S. (2006). The daily show effect. Candidate evaluations, efficacy and American youth. American Politics Research, 34(3), 341-367.

Beck, Ulrich (1998). ¿Qué es la globalización? Barcelona: Paidós.

Bell, Daniel (1977). Las contradicciones culturales del capitalismo. Madrid: Alianza. 
Bernhardt, Dan, Krasa, Stefan y Polborn, Mattias K. (2006).Political Polarization and the Electoral Effects of Media Bias. Journal of Public Economics, 92(5-6), 1092-1104.

Berrocal, Salomé (2003). Comunicación política en televisión y nuevos medios. Barcelona: Ariel

Berrocal, Salomé (Ed.) (2017). Politainment: la política espectáculo en los medios de comunicación. Valencia: Tirant.

Berrocal, Salomé, Campos-Domínguez, Eva y Redondo, Marta (2012). El infoentretenimiento en Internet. Un análisis del tratamiento político de José Luis Rodríguez Zapatero, Mariano Rajoy, Gaspar Llamazares y Rosa Díez en YouTube. Doxa Comunicación, 15, 13-34.

Blumer, Jay y Gurevitch, Michael (1995). The crisis of political communication. London: Routledge.

Bohman, James y Rehg, William (Eds.) (1997). Deliberative Democracy: Essays on Reason and Politics. Cambridge (MA): MIT Press.

Brennan, Jason (2016). Against Democracy. Princeton (NJ): Princeton University Press.

Casero-Ripollés, Andreu (2012). El periodismo político en España: algunas características definitorias. Sociedad Latina de Comunicación Social, $19-46$.

Casero-Ripollés, Andreu, Ortells-Bádenes, Sara y Rosique Cedillo, Gloria (2014). La espectacularización de la política. Consecuencias democráticas de la disolución de las fronteras entre información, entretenimiento y privacidad en la era digital. Telos: Cuadernos de comunicación e innovación, 99, 45-54.

Chaiken, Shelly y Eagly, Alice H. (1976). Communication modality as a determinant of message persuasiveness and message comprehensibility. Journal of Personality and Social Psychology, 34, 605-614.

Conill, Jesús y Gozálvez, Vicent (Eds.) (2004). Ética de los medios. Una apuesta por la ciudadanía audiovisual. Barcelona: Gedisa.

Contreras, José Miguel y Palacio, Manuel (2001). La programación de televisión. Madrid: Síntesis.

Cortina, Adela (1993). Ética aplicada y democracia radical. Madrid: Tecnos. 
Cortina, Adela (2011). Neuroética y neuropolítica. Madrid: Tecnos.

D’Adamo, Orlando y García-Beaudoux, Virginia (2016). Comunicación Política: narración de historias, construcción de relatos políticos $\mathrm{y}$ persuasión. Comunicación y Hombre, 12, 23-39.

Dubiel, Helmut (1993). ¿Qué es neoconservadurismo? Barcelona: Anthropos.

Echeverría, Martín (2017). Personalización política e infoentretenimiento periodístico. Un estudio desde los encuadres. Cuadernos.info, 41, 71-87.

García-Marzá, Domingo (2013). Neuropolítica y democracia: un diálogo necesario. Daimon, 59, 171-182.

García-Marzá, Domingo (2016). Enfoques mesodeliberativos: sobre la articulación institucional en las democracias deliberativas. Isegoría, 54, 147-170.

Giddens, Anthony (1979). La estructura de clases en las sociedades avanzadas. Madrid: Alianza.

Habermas, Jürgen (1973). Problemas de legitimación en el capitalismo tardío. Buenos Aires: Amorrortu.

Habermas, Jürgen (1997). Política conservadora, trabajo, socialismo y utopía hoy. En Habermas, Jürgen. Ensayos políticos. Barcelona: Península.

Habermas, Jürgen (2010a). Teoría de la acción comunicativa. Madrid: Trotta.

Habermas, Jürgen (2010b). Facticidad y validez. Madrid: Trotta.

Hatfield, Elaine, Cacioppo, John T. y Rapson, Richard (1994). Emotional Contagion. Cambridge: Cambridge University Press.

Henn, Matt, Oldfield, Ben y Hart, James (2018). Postmaterialism and young people's political participation in a time of austerity. The British Journal of Sociology, 69(3), 712-733.

Hobsbawm, Eric (2011). Historia del siglo XX. Barcelona: Crítica.

Honneth, Axel (1994). Desintegration. Bruchstücke einer soziologischen Zeitdiagnose. Frankfurt a.M.: Fischer Taschenbuch Verlag. 
Honneth, Axel (2011). Conciencia moral y dominio social de clases. En Honneth, Axel. La sociedad del desprecio (55-73). Madrid: Trotta.

Inglehart, Ronald (1971). The Silent Revolution in Europe: Intergenerational Change in Post-Industrial Societies. American Political Science Review, 65 (4), 991-1017.

Inglehart, Ronald (1999). Trust, well-being and democracy. En Warren,

Mark E. (ed). Democracy and Trust (88-120). Cambridge: Cambridge University Press.

Inglehart, Ronald (2008). Changing Values among Western Publics from 1970 to 2006. West European Politics, 31(1-2), 130-146.

Innerarity, Daniel (2015). La política en tiempos de indignación. Barcelona: Galaxia Gutenberg.

Jacobs, Lawrence R. y Shapiro, Robert Y. (2000). Politicians Don't Pander. Political Manipulation and the Loss of Democratic Responsiveness. Chicago: University of Chicago Press.

Keynes, John Maynard (1986). Teoría general de la ocupación, el interés y el dinero. México: FCE.

Kovach, Bill y Rosenstiel, Tom (2012). Los elementos del periodismo. Madrid: Aguilar.

Lozano-Rendón, José Carlos (2004). Espectacularización de la información en noticieros televisivos de Canadá, Estados Unidos y México. Diálogo Político, 21(1), 102-115.

Lübbe, Hermann (1998). Gegenwartsschrumpfung. En Backhaus, Klaus y Bonus, Holger (Eds.). Die Beschleunigungsfalle oder der Triumph der Schildkröte (129-164). Stuttgart: Schäffer/ Pöschel.

Macpherson, Crawdor B. (2003). La democracia liberal y su época. Madrid: Alianza.

Mancini, Paolo y Swanson, David L. (1996). Politics, media and modern democracy: introduction. En Swanson, David L. y Mancini, Paolo (Eds.). Politics, media and modern democracy. An international study of innovations in electoral campaigning and their consequences (126). New York: Praeger Publishers.

Marcuse, Herbert (1985). El hombre unidimensional. Barcelona: Planeta. 
Margolis, Michael y Mauser, Gary A. (1992). The Politics of Gun Control: Comparing Canadian and American Patterns. Environment and Planning C: Government and Policy, 10, 189-209.

Marx, Karl (1970). Contribución a la crítica de la economía política. Madrid: Alberto Corazón Editor.

Mazzoleni, Gianpietro (2004). La comunicazione politica. Bologna: Il Mulino.

Moulier Boutang, Yann (2004). Riqueza, propiedad, libertad y renta en el capitalismo cognitivo. En Blondeau, Olivier et al. (Eds.). Capitalismo cognitivo, propiedad intelectual y creación colectiva. Madrid: Traficantes de Sueños.

Mosco, Vincent (2009). The political economy of communication. London: Sage.

Muñoz-Alonso, Alejandro y Rospir, Juan Ignacio (Eds.) (1995). Comunicación política. Madrid: Universitas.

Nimmo, Dan y Savage, Robert L. (1976). Candidates and their imagen. Santa Monica, California: Goodyer Publishing Co.

Offe, Claus (1988). Partidos políticos y nuevos movimientos sociales. Madrid: Sistema.

Offe, Claus (1990). Contradicciones en el Estado del bienestar. Madrid: Alianza.

Ordóñez, Vicente, Feenstra, Ramón A. y Tormey, Simon (2015). Citizens against Austerity: a Comparative Reflection on Plataforma de Afectados por la Hipoteca (PAH) and Bündnis Zwangsräumung Verhindern (BZV). Araucaria. Revista Iberoamericana de Filosofía, Política y Humanidades, $17(34), 133^{-154}$.

Orejuela, Sandra (2009). Personalización política: la imagen del político como estrategia electoral. Revista de comunicación, 8, 60-83.

Ortells-Bádenes, Sara (2011). La consolidación de los programas de infoentretenimiento en el panorama televisivo español. Fórum de recerca, 16, 279-292.

Pardo, José Luis (2018). El malestar en la política. En VV. AA. La era de la perplejidad: repensar el mundo que conocíamos. Serie anual BBVA. 
Pereira, Gustavo (2007). ¿Condenados a la desigualdad extrema? México: Centro de Estudios filosóficos, políticos y sociales Vicente Lombardo Toledano.

Pérez-Zafrilla, Pedro Jesús (2018). Marcos mentales: ¿marcos morales? Deliberación pública y democracia en la neuropolítica. Recerca, 22, 91-110.

Pettit, Philip (1999). Republicanismo: una teoría sobre la libertad y el gobierno. Barcelona: Paidós.

Piketty, Thomas (2014). El capital en el siglo XXI. Madrid: FCE.

Rodríguez-Polo, Xose Ramón y Martín-Algarra, Manuel (2012). Los principios del sistema liberal de medios ante la crisis de la comunicación pública. Una aproximación crítica. Vivat Academia, 117, 77-90.

Romero, Joan y Ariño, Antonio (2016). La secesión de los ricos. Barcelona: Galaxia Gutemberg.

Rosa, Hartmut (2005). Beschleunigung. Die Veränderung der Zeitstrukturen in der Moderne. Frankfurt am Main: Suhrkamp.

Rousseau, Jean Jaques (1988). El contrato social. Madrid: Tecnos.

Salgado Losada, Alejandro (2010). Actualidad, humor y entretenimiento en los programas de televisión: de la terminología a la realidad profesional. Trípodos, 27, 59-73.

Sampedro, Víctor y Seoane, Francisco (2008). The 2008 Spanish General Elections: "Antagonist Bipolaritazion" Geared by Presidential Debates, Partinanship and Media Interestins. The International Journal of Press/Politics, ${ }_{13}$ (3), 336-344.

Schumpeter, Joseph (1988). Capitalismo, socialismo y democracia. Barcelona: Orbis.

Schwartzenberg, Roger-Gérard (1977). L'État Spectacle, Le Star System en politique. Paris: Flammarion.

Taylor, Charles (1994). La ética de la autenticidad. Barcelona: Paidós. Thurow, Lester C. (1996). El futuro del capitalismo. Barcelona: Ariel. Uribe, Rodrigo y Gunter, Barrie (2007). Are "Sensational" News Stories More Likely to Trigger Viewers' Emotions than Non-Sensational 
New Stories? A Content Analysis of British TV News. European Journal of Communication, 22(2).

Vázquez-Sande, Pablo (2017). Personalización de la política, storytelling y valores transmitidos. Communication \& Society 3o(3), 275-291.

Westen, Drew (2008). The Political Brain. New York: Public Affairs. 